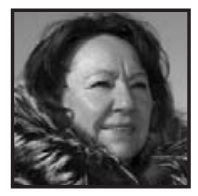

\title{
Life Lessons From the Arctic
}

\author{
Sheila Watt-Cloutier
}

\begin{abstract}
Sheila Watt-Cloutier grew up in Kuujjuaq, a small village in Northern Quebec. In this interview she relates how growing up in a traditional Inuit hunting culture gave her a deep sense of connection-an essential element for the work she does today as a climate change awareness advocate. She applauds the environmental efforts of individuals at the grassroots level but feels very strongly that governments and policymakers must come on board to effect true, lasting change. She believes that our educational system has a key role to play in helping to reduce climate change and she is encouraged to see young people becoming "natural" conservationists. She says that the future of education lies in providing a more holistic approach so that people can develop this sense of connection with a focus on humanity and sustainability instead of just economics. Finally, she offers a quick preview of what to expect in her upcoming book.
\end{abstract}

Sheila, I understand you grew up in Kuujjuaq, a small village in Northern Quebec. What is it about your education, either formal or informal, that helped you to become the human rights and climate change advocate that you are?

$\mathrm{t}$ all starts back to the very foundation that I had as a young child growing up in the Inuit hunting culture, which gave me I think the basis of an appreciation and respect for all that is around me, which of course then throughout my entire life has been the focus and the strength coming from that very remarkable resilient culture. I grew up travelling on the ice and snow, travelling only by dog team in the winter and canoe in the summer, and we lived quite traditionally in those years. So the appreciation of the land and the ice and the bounty of the land and the ice in terms of the connection to our country food, the wildlife that we hunt, gave me that 
start in terms of the connection-the environment, the weather, the wildlife, the nature-all of those things are just the most remarkable places in which one finds oneself I guess very young, and the connection to family and connection to community also is a very important aspect of the education and how all that connects because there's a real difference of course, as we know, between formal schooling and education, and education is very much an all-encompassing way in which we teach our children and I will certainly get into that in a few minutes.

What are the most important things that need to be done to preserve the Arctic and reduce the pace of climate change?

There is a lot to be done and even though civil society today seems to be, often times I would say, ahead of our own governments around the world, I think because of the Arctic story, because of many other vulnerable places in the world that are being negatively impacted by climate change and how people are starting to see this issue so much more as a human issue rather than just an academic or scientific or economic issue-people are starting to connect to that. At the grassroots level, I think there is a huge movement that is happening as the result of that "connect" that people have started to make with the vulnerable peoples of the world including, of course, the Arctic. But monumental change or the great change has to happen at a much grander scale, meaning it is on the scale of governments and industry that policies have to be developed, whether they are economic, industry and so on.

I think civil society in what they are doing is just tremendous. I'm not minimizing what people are now starting to do in their homes, how differently they are starting to deal with issues even at their home level, at their municipality level, but I think the bigger issues here at hand have to be done where people have to start to vote differently in terms of leadership for leaders that are really committed to these issues, so that policies at the bigger scale of industry and policies at governmental levels in terms of environmental policies have to kick in. And that really hasn't been able to happen even though the intention has been good in our previous governments here in Canada, certainly in the United States now the presidency and the administration have changed and there's a real commitment to make change. But there are still a lot of challenges at play where most people are not willing to take the huge steps that are required to make the changes in lowering greenhouse gas emissions.

In all of what I'm saying there is positive movement but there has to be so much more that needs to be done, and that is in how we vote for leaders and how 
those leaders have to become much more committed to the longer-term and larger picture in terms of what is happening in the Arctic because the Arctic has huge global significance and most people have not understood that very well, that the Arctic indeed is the cooling system, the air conditioner so to speak for the globe. And so if that starts to go, then there are going to be major problems that we already see evidence of that around the world in terms of what is happening with more and more intense hurricanes, more and more floods, more and more droughts. All of these issues are all extremely connected to what is happening here in the Arctic.

How can our educational systems help to reduce climate change?

I think education systems and the schooling systems in fact have a huge responsibility to play, because in the work that I have been doing in terms of connecting with schools, whether they are even sometimes at the elementary level, but most times it is at the university level, that I am speaking, either at convocations or at events that universities have initiated in terms of addressing these issues of climate change, but there is a lot of hope in our schools, there is a lot of hope in our education system.

The students and the children are our future, and I see a real evidence particularly in those groups of young people who are staunchly becoming very good natural conservationists so to speak and also great environmentalists. I think the schools have great potential to start to teach and create some really strong curriculum in these areas, because I'm finding that the more the students learn the more they put pressure on their own parents and their own leaders to do the right thing, and so I think there is a great responsibility to be had in our education system in terms of changing this whole thing around.

What do you believe should be done in elementary schools by the teachers to raise awareness about the environmental state of the world?

Well, I have always said that when you learn what is going on in the Arctic, it becomes the place in which all things then connect. And so I always say that if you can create an awareness in students and create good information, a good science, the good human stories that will allow them to connect to this as a real human issue, not just a scientific issue, not just of ice and polar bears, but of the actual people who live in the Arctic and who live in other places around the world because as the Arctic is 
melting we're keenly aware that other places in the world are sinking. That's how connected we are because you can't get any clearer than that in terms of understanding connectivity when you know that Greenland is melting and the ice sheets are melting, that other places in the world are sinking. And most of the time it is the poor, the vulnerable and the indigenous peoples who are coastal peoples who remain extremely connected to a nature and to their food source that are most negatively impacted and who have the least sophisticated mechanisms to deal with and adapt to these monumental changes that are happening.

So I think when we get students to understand these connections through strong, good curriculum, then that's the way to go. Kids understand these connections very quickly, and I think it's through developing those kinds of programs in schools that this will be a great start. Of course, the other issues at play which I have said earlier is that kids start to become their own really good strong environmentalists and become keenly aware of what is working and what is not, what is waste, what is not, and how to be much more cautious about their daily lives. All of these things put together are ways in which teachers and education systems, schooling systems can start these things and put them into process.

\section{Do you have any additional thoughts about education for the future?}

Well, I have a lot of thoughts on education for the future in terms of how disconnected the world has become. I have always said that I think in terms of education, for us, first of all, the Inuit culture is based on a very holistic way of teaching your children. It is not just about the technical aspect; we are a hunting culture, but it's not just about the technical aspect of the hunt. It is very holistic in the sense that when children are taught to go out onto the land or onto the ice into nature, you're taught the holistic way in which life is. In fact, you are taught not just to aim the gun and skin the seal and cut up the meat and so on, which is a very important part of the hunt of course, but at the same time while you're out there you are taught the characterbuilding skills, and that is just as important, if not more sometimes, in the sense that it's very holistic but it's not just to teach you how to survive the environment up here in the Arctic, but these skills are very transferable to the modern world. What I mean by that is when you go out, automatically as you're waiting for the snow to fall and the ice to form, you are taught patience. When you're out there waiting for the animals to surface in some way, you are taught patience immediately. You are taught how to be courageous and bold under pressure when you need to. You are taught all of the survival skills that are just so important, yes to survive, but these are very trans- 
ferable as I said earlier, and you are taught how to be courageous at the right time and to take these kinds of survival base skills which are just so important in developing the confidence and your sense of self-worth and your sense of real keen judgment that one requires to survive these kinds of conditions up here in the Arctic.

Ultimately, it's sound judgment and wisdom that you are taught as you are out there on the land and the ice. These are the very skills that often times are separated from the formal institutions of learning, and often times, character is not part of the course. Whereas, for us in the holistic way, it is very much a part of the course and it really needs to be there because if you have bad judgment or if you're impulsive, for example, one of the things that we're discovering is that the land if you're impulsive, you just are going to be that way in your life and when things come up where you have peer pressure and you have all kinds of things coming at you in stressful situations that you have this impulsive need to either end your pain or do something but not with good judgment. So we're also learning with all of these problems that we face in the Arctic where we've had tumultuous change in a very short period of time, we've had historical traumas that have affected us in terms of forced relocation and all of these tremendous changes that have happened so quickly from going from a traditional way of life to this modern world and not being able to deal and cope with some of these stresses. We're realizing that impulsivity is also at the root of some of the high suicide rates that we have in the Arctic.

These are really valuable life skills and character skills that are taught on the land and the ice, which have been severed when we moved into formal education. We're starting to see that the holistic way in which we have taught our children is really the way that we need to continue if we want our children to survive the modern world because when you are taught the kind of patience and the right judgment and how not to be impulsive and how to be bold under pressure and how to withstand stress out on the land, then that gets integrated into one's ability to withstand all of these other stresses in the modern world. It's a very holistic way, so I think as we're getting into these issues of environmental degradation of the Arctic, we're finding that it is because of these disconnects that the urban settings have had and continues to have in terms of their own connections to each other, to themselves, to their neighbours, to their municipality and certainly to their environment, that we are dealing with this disconnect. That's why we're debating this issue of climate change in the first place because not everyone in the urban setting in the larger world connects in this way as we continue to as Inuit of the Arctic-and not to say that we're the only ones, that because I'm coming from that perspective I'm giving you that story from my perspective and what we're going through here. It's so much more than meets the 
eye in terms of climate change that when people talk about the protection of the ice and the snow and the polar bears and so on, it's so much more than that. It's about our youth who are not necessarily effectively making it in this new world order of globalization.

I understand you are in the process of writing a book. Could you tell us a little bit about that?

I have been promising this book for some years now but it's because I have remained rather busy in terms of speaking engagements and being quite busy being active doing this advocacy and speaking work around the world in the last four years since I left elected politics with ICC [Inuit Circumpolar Council] that it has taken this long. It is a book that has certainly been wanting to emerge and be written, certainly from a larger place in myself. As I've always said this work is so much bigger than myself, and I have felt very compelled to write this book based on all of these things that I talk about but in a much more in-depth way, not just at a 50-minute keynote talk, or a 20-minute article or whatever the case may be. I want to write, and I've started to write, and I will finish by next summer because I am now off to Bowdoin College to teach for a short period of time per week. I've been invited to be a visiting scholar there, but in a sense it's a writing retreat for the year and I will finish it and it is about connectivity.

It is about the human story: it is about making these kinds of connections of how very important Inuit culture is to the rest of the world, that we are not just powerless victims over these matters. Also, I want to try to get people to start thinking about this whole rush to the Arctic now. You know no one cared about the Arctic so much as long as it remained ice and cold and snow. But now that things are warming up-and now that there's a possibility of the Northwest Passage opening up, and the resources, the rich resources that lie beneath the melting ice are starting to open up-there seems to be this keen, keen interest in coming up now once again to exploit the Arctic and explore it. For me, the Arctic is not some frontier, it's not wilderness, it is our homeland and again for me it's just the most precious place-of course I'm biased-in the world, and I think we all need to come together to protect this. I think people have to understand that the very thing that the Arctic is now challenged with in terms of the greenhouse gas emissions and all of the pollutants that end up here in the Arctic, and so on. Even with all of that and because of the incredibly irresponsible way, I would say, our own governments have dealt with us, that has now led to, of course, the highly dependent people that we have become, whether it's to 
substances or to institutions or processes, because of all the historical trauma, the dependencies really are at the root of the dispiritedness that is happening in our communities. So, for me, the understanding has to be, if we are getting into this whole area once again of exploiting and development - the very thing that is creating havoc with our climate-because we're in this place of vulnerability in the Arctic, that even the worst things that could possibly make the tipping point happen here, is the very thing that we now think might be the solution.

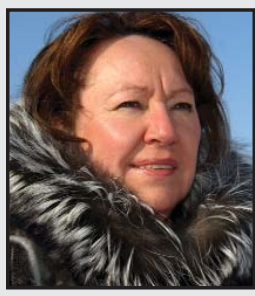

Sheila Watt-Cloutier is an advocate for climate change initiatives and is influential among development groups and policy leaders around the world. Based in Nunavut, she is a political spokesperson for the Inuit, who feel the fall-out from climate change more immediately and dramatically than most.

From 1998 to 2006, Watt-Cloutier was the International Chair of the ICC (the Inuit Circumpolar Council), which represents the more than 150,000 Inuit of Canada, the United States, Greenland, and Russia. Her negotiations in this role led to a global treaty banning POPs (persistent organic pollutants). For this historic signing, she received the inaugural Global Environmental Award from the World Association of NonGovernmental Organizations. In addition to her environmental work, she was the Corporate Secretary of Makivik Corporation, which looked after the funds from the 1975 James Bay and Northern Quebec Land Claims Agreement.

Sheila Watt-Cloutier is a recipient of a UN Lifetime Achievement Award for Human Development, the Global Green USA Award for International Environmental Leadership, and is also an Officer of the Order of Canada.

LINK TO:

www.isuma.tv 